\section{Assessment of residual curarization using low-current stimulation}

Sorin J. Brull MD, Jan Ehrenwerth MD, Neil R. Connelly MD, David G. Silverman MD
The present study employed train-of-four (TOF) stimulation at a current of $20 \mathrm{~mA}$ to assess the incidence and degree of residual neuromuscular blockade in 64 randomly selected Post Anesthesia Care Unit (PACU) patients. Group C (Control, $n=10)$ had received anaesthesia without nondepolarizing muscle relaxam: Group V $(n=25)$ had received vecuronium; and Group $P(n=$ 29) had received pancuronium. At the end of surgery, each patient had been considered by his anaesthetist to have adequate neuromuscular function on the basis of clinical signs and tactile or visual evaluation of responses to TOF stimulation. However, upon testing in the PACU 15 min later, 45\% (13 of 29) of Group $P$ patients and $8 \%$ ( 2 of 25 ) of Group $V$ patients had a TOF ratio $<0.70$. This study indicates that residual curarization may be commonly encoumlered following long-acting relaxants despite qualitative intraoperative TOF moniloring. The present incidence, detected at a current of $20 \mathrm{~mA}$, is consistent with previous reports which employed supramarimal TOF stimulation. We conclude that despite intraoperative monitoring, residual curarization following long-acting nondepolarizing agents is common and that it may be detected with TOF at a low stimulating current $(20 \mathrm{~mA})$.

La présente étude a utilisé l'ondée-de-quatre (TOF) avec des courants de $20 \mathrm{~mA}$ afin d'évaluer l'incidence el le degré de blocage neuromusculaire résiduel chez 64 patients choisis au

\section{Key words}

MEASUREMENT TECHNIQUES: neuromuscular blockade, train-of-four:

NEUROMUSCULAR RELAXANTS: pancuronium, vecuronium;

RECOVERY: residual curarization.

From the Department of Anesthesiology, Yale University School of Medicine, Yale-New Haven Hospital, New Haven, CT 06510.

Presented in part at the Annual Meeting of the American Society of Anesthesiologists, San Francisco, CA, October $8-12,1988$

Address correspondence to: S. J. Brull, Department of Anesthesiology - T3, Yale University School of Medicine, 333 Cedar Street, P.O. Box 3333, New Haven, CT 06510 Accepted for publication 10th October, 1990. hasard dans l'unité des soins postanesthésiques (PACU). Le groupe $C$ (Contrôle, $n=10$ ) a resu de l'anesthésie sans relaxant musculaire nondépolarisant; le Groupe $V(n=25) a$ reçu du vécuronium: et le Groupe $P(n=29)$ a reçu du pancuronium. A la fin de la chirurgie, chaque patient fut considéré par son anesthésiste comme ayant une fonction neuromusculaire adéquate sur la base des signes cliniques tactiles et les évaluations visuelles des réponses de la stimula tion avec une ondée-de-quatre. Cependant, lors de la stimula. tion au PACU 15 minutes plus tard. 45\% (13 de 29) du Groupe de patients $P$ et $8 \%$ ( 2 de 25 ) avaient un ratio de TOF $<0,70$. Cette étude indique que la curarisation résiduelle peur survenir fréquémment après les relaxants à longue action malgré une surveillance qualitative intraopératoire du TOF. L'incidence trouvée, détectée avec un courant de $20 \mathrm{~mA}$, est en accord avéc des études antérieures qui émploient la stimulation supramaximale de TOF. On conclut que malgré une surveillance intraopératoire, la curarisation résiduelle après des agents nondépolarisants à longue action est fréquemle et qu' elle pourrait être détectée par une stimulation avec un TOF avec un couram de $20 \mathrm{~mA}$.

In the past decade, several investigators have noted that, despite apparently adequate clinical reversal of neuromuscular blocking (NMB) agents, a considerable number of patients showed evidence of inadequate neuromuscular function when tested in the post-anaesthesia care unit (PACU). ${ }^{1-5}$ Recent evidence has suggested that this problem is less common following reversal of newer relaxants of intermediate duration. ${ }^{4-6}$

Despite the high incidence of residual blockade, neurostimulation in the PACU is used infrequently as it can be uncomfortable for awake patients. ${ }^{7}$ We recently reported that train-of-four (TOF) stimulation with 20 and 30 milliampere ( $\mathrm{mA}$ ) currents consistently provided TOF ratios comparable with those obtained using a supramaximal current of $50 \mathrm{~mA} .^{8}$ This may be important in testing awake patients, since higher stimulating currents are associated with more discomfort. ${ }^{7.8}$ The present report assesses whether an incidence of residual blockade comparable to that reported at other institutions could be identified by neuromuscular testing at a submaximal current of $20 \mathrm{~mA}$ in the $64 \mathrm{PACU}$ patients evaluated in our 
previous study. ${ }^{8}$ In contrast to several recent reports, ${ }^{1-5}$ all patients in the present study had been assessed intraoperatively with a blockade monitor to guide maintenance of NMB therapy. Moreover, in distinction to a previous report where a blockade monitor was employed in $74 \%$ of patients intraoperatively to monitor the level of blockade but not necessarily to assess the adequacy of reversal, ${ }^{4}$ all patients in the present study were also lested for adequacy of reversal by visual or tactile responses to neurostimulation.

\section{Methods}

For the present iivestigation, consistent delivery of a 20 $\mathrm{mA}$ current by a Digistim III nerve stimulator (Neuro Technology Inc., Houston, TX) was first confirmed by comparing its LCD display to the voltage generated on an interfaced Tektronix 7623A (Tektronix Inc. Beaverton, OR) oscilloscope. A decade box provided variable resistances ranging from 470 to $2,200 \mathrm{ohms}$.

Following approval by the institutional Human Investigation Committee, 64 patients who were sufficiently awake and cooperative were studied within 15 min of PACU arrival. Patients were excluded from analysis if they were $<18$ or $>90$ yr of age, $<50 \%$ or $>150 \%$ of ideal body weight, ASA physical status 4 or 5 , if they had a known or suspected history of neuromuscular disease or were receiving medications known to affect neuromuscular function. Patients were assessed by: (1) ability to sustain head-lift for five seconds; and (2) TOF stimulation at $20 \mathrm{~mA}$. For TOF testing, surface electrodes were placed over the olecranon groove and volar forearm, and the ipsilateral thumb was inserted in a calibrated adductor pollicis monitor (Medar Corp., Scarsdale, NY) interfaced to a monitor and a stripchart recorder (Datascope 2000A/RS, Datascope Corp., Paramus, NJ). The ratio of the fourth to the first twitch $\left(T_{4} / T_{1}\right.$ ratio) was then determined after each of two sets of TOF stimulation at $20 \mathrm{~mA}$ with a 20 -sec interval between sets, and the difference between these readings was calculated.

Patients were categorized retrospectively according to their intraoperative anaesthetic regimen: control group (C) received regional or general inhalational anaesthesia (enflurane or isoflurane) without nondepolarizing agents $(n=10)$; vecuronium group $(V)$ received general inhalational anaesthesia (halothane, enflurane or isoflurane) with vecuronium as the sole nondepolarizing agent $(n=$ 25 ); and pancuronium group $(P)$ received general inhalational anaesthesia (enflurane or isoflurane) with pancuronium as the sole nondepolarizing agent $(n=29)$. The investigator had been blinded to intraoperative technique, and the anaesthesia care provider had not been informed that the patient would be evaluated postoperatively.

Analysis was performed as follows: the three patient

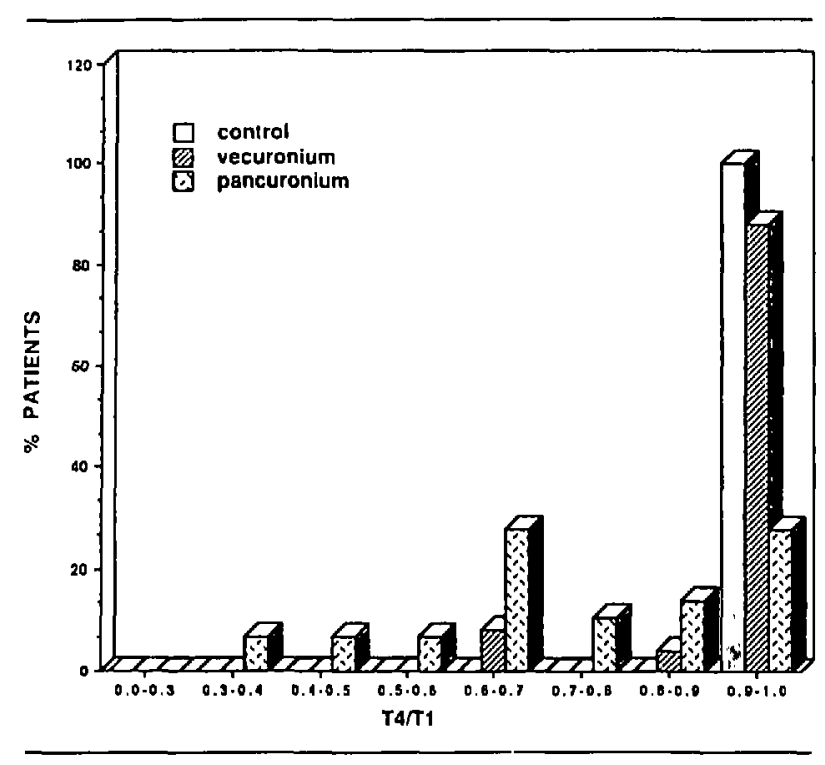

FIGURE Train-of-four ratios during testing in the PACU. Bars represent distribution of $T_{4} / T_{1}$ ratios in the three patient groups.

groups were compared with regard to $T_{4} / T_{1}$ ratio using Wilcoxon rank sum test. The incidence with which the $T_{4} / T_{1}$ ratio was less than 0.70 , ASA status classification, inhalational and intravenous anaesthetics received, antibiotics received, ability to maintain head-lift, and the sex distribution among the three groups were compared with chi-square analysis. The differences in age, weight, temperature, duration of anaesthesia, initial and maintenance doses of NMB agents, time from last dose of relaxant to time of testing of TOF, and dose of reversal agents were compared using ANOVA with Duncan's multiple range test for multiple comparisons

\section{Results}

Testing of the neuromuscular monitor confirmed consistency of current output at the resistances tested. For an LCD reading of $20 \mathrm{~mA}$, the Tektronix oscilloscope readings were $23.5,22.1,20.9$ and $19.5 \mathrm{~mA}$ at resistances of $470,1000,1500$ and 2200 ohms, respectively. During clinical testing, the mean difference between the two successive $T_{4} / T_{1}$ determinations at $20 \mathrm{~mA}$ was $<2 \%$, and the first $T_{4} / T_{1}$ determination was therefore used for subsequent analyses.

Despite being considered adequately reversed while still in the operating room at the end of surgery, 15 of the 64 patients evaluated had a $T_{4} / T_{1}<0.70$ when tested in the PACU. As noted in the Figure, 13 of the 29 patients $(45 \%)$ in Group $P$ had a $T_{4} / T_{1}$ ratio $<0.70$. In contrast, only two of 24 patients ( $8 \%$ ) of Group $V$ and no Group $C$ patients evidenced a $T_{4} / T_{1}$ ratio $<0.70$. The two Group $V$ patients who showed a $T_{4} / T_{1}<0.70$ in the PACU (i.e., 
TABLE I $T_{4} / T_{1}$ ratio at $20 \mathrm{~mA}$

\begin{tabular}{lll}
\hline & Mean $\pm S D$ & Range \\
\hline Group $C(n=10)$ & $0.98 \pm 0.04$ & $0.92-1.03$ \\
Group $V(n=25)$ & $0.94 \pm 0.09$ & $0.65-1.00$ \\
Group P $(n=29)$ & $0.72 \pm 0.20^{*}$ & $0.32-1.00$ \\
\hline
\end{tabular}

$* P<0.05$ for Groups $P$ vs $C$ and $P$ vs $V$.

ratios of 0.63 and 0.65 ) were the (wo who had received a relatively large dose of vecuronium $\left(0.25 \mathrm{mg} \cdot \mathrm{kg}^{-1}\right)$ to facilitate rapid intubation. Overall, patients who received pancuronium (Group $P$ ) had a mean $T_{4} / T_{1}$ ratio of $0.72 \pm$ 0.20 , which was lower than the mean values of 0.98 and 0.94 for Groups $C$ and $V$, respectively $(P<0.05$ for Group P vs $\mathrm{V}$ and Group P vs C) (Table I).

Sixty-one of the 64 patients were sufficiently awake and cooperative to undergo clinical testing (i.e., head-lift) in the PACU. One patient was unable to sustain head-lift for five seconds; this Group P patient had a $T_{4} / T_{1}=0.37$. The three patients who were unable to cooperate with clinical testing were likewise all in Group P; their TOF ratios were $0.43,0.94$, and 0.97 . All patients in Group $P$ and 23 of the 25 patients in Group $V$ received neostigmine and glycopyrrolate at the conclusion of surgery (NS for difference between groups with respect to dosage).

Mean duration from the start of anaesthesia to the time when patients arrived in the PACU (i.e., total anaesthesia (ime) was $200 \mathrm{~min}$ for Group $\mathrm{P}$, longer than for both Group C (145 min) and Group V (146 min $)(P<0.05)$. There were no significant differences with respect to age, sex, ASA physical status, antibiotic therapy, dose of reversal agents, duration from reversal to time of TOF testing, or incidence of intraoperative hypo- or hyperthermia (Table II).

\section{Discussion}

The current study corroborates previous reports ${ }^{1-6}$ that "residual" neuromuscular blockade, defined by a $T_{4} / T_{1}$ ratio $<0.70$, is common. The $45 \%$ incidence of residual blockade following the use of pancuronium and the $8 \%$ incidence following the use of vecuronium observed in the present study confirm the lesser likelihood of residual blockade when shorter-acting agents are used. This difference may be attributed to the longer half-life of pancuronium and to the existence of active metabolites. The former difference appeared to have been nullified when a high dose of vecuronium $\left(0.25 \mathrm{mg} \cdot \mathrm{kg}^{-1}\right)$ was used. Differing affinities for presynaptic receptors and/or tendencies for channel block may further contribute to the difference in residual effects of relaxants.

Ideally, intraoperative monitoring should document both readiness for reversal as well as adequacy of
TABLE II Mean demographic values

\begin{tabular}{lllll}
\hline & Group C & Group $V$ & Group P & $P$ values \\
\hline Age (yr) & 47 & 40 & 50 & NS \\
Weight (kg) & 74 & 72 & 64 & NS \\
$\begin{array}{l}\text { Temperature in PACU } \\
\quad\left({ }^{\circ} \text { C) }\right.\end{array}$ & 35.6 & 36.0 & 35.7 & NS \\
$\begin{array}{l}\text { Neostigmine dose (mg) } \\
\text { Duration of surgery }\end{array}$ & - & 2.4 & 3.2 & NS \\
$\quad 1$ min) & 146 & 149 & 202 & $\begin{array}{l}P<0.05 \text { for } \\
\text { Group P vs V } \\
\end{array}$ \\
& & & & Group P vs C \\
\hline
\end{tabular}

subsequent recovery. In the present study, partial PACU curarization was not avoided by intraoperative visual and tactile assessment of the responses to TOF and/or tetanic stimulation. If partial curarization is due to only partial reversal (i.e., is "residual"), then more effective intraoperative monitoring is required. Although mechanographic assessment of response to supramaximal neuromuscular stimulation is the standard for assessment of residual blockade, its intraoperative use is limited by relatively elaborate set-ups. Alternatively, it has been shown that the absence of fade to TOF stimulation by tactile and visual means does not exclude partial curarization. ${ }^{9}$ Perhaps qualitative assessment by double-burst stimulation ${ }^{10.11}$ or less cumbersome electromyographic and accelerographic techniques ${ }^{12,13}$ will be helpful.

Postoperatively, neuromuscular testing is further limited by patient discomfort. The use of less painful, submaximal stimulating currents may facilitate such monitoring. ${ }^{7}$ The consistency of the $T_{4} / T_{1}$ ratio in response to currents of 20,30 and $50 \mathrm{~mA}$ has recently been reported ${ }^{8.14}$ An inter-current difference of less than $2 \%$ was noted for $T_{4} / T_{1}$ ratios (ranging from 0.1 to 1.0 ) obtained mechanographically, as long as all four twitches were detectable at the lower currents. ${ }^{8.9}$ All PACU patients in the current investigation were able to demonstrate four twitches to TOF stimulation, and testing at 20 $\mathrm{mA}$ proved to be consistent and well-tolerated.

Our findings are similar to other reports which have documented the inability to detect residual blockade in PACU patients using clinical criteria (Table III). The lack of sensitivity of head-lift testing to detect blockade in the present study was demonstrated by the fact that only one patient who was awake enough to cooperate with clinical testing was unable to sustain head-lift for more than five seconds. This patient had a TOF ratio of 0.37 and was in Group P.

It should be noted that there is controversy with respect to both the TOF value and to the clinical tests which indicate adequate reversal. Dupuis et al. ${ }^{17}$ have documented the differences between electromyographic and 


\begin{tabular}{|c|c|c|c|c|c|}
\hline \multirow{2}{*}{$\begin{array}{l}\text { Author and } \\
\text { year of siudy }\end{array}$} & \multicolumn{2}{|c|}{$\begin{array}{l}\text { No. and percent of } \\
\text { patients able to } \\
\text { cooperate with } \\
\text { clinical resing }\end{array}$} & \multirow{2}{*}{$\begin{array}{l}\text { No. of } \\
\text { patients } \\
\text { with TOF } \\
\text { rario }<0.70\end{array}$} & \multirow{2}{*}{$\begin{array}{l}\text { No. of } \\
\text { patients } \\
\text { clinically } \\
\text { weak with } \\
\text { TOF ratio } \\
<0.70\end{array}$} & \multirow{2}{*}{$\begin{array}{l}\text { No. of } \\
\text { patielts } \\
\text { weak } \\
\text { TOF } \\
>0.70\end{array}$} \\
\hline & $n$ & $\%$ & & & \\
\hline Lennmarken-1984 ${ }^{3}$ & 46 & (96) & 12 & 3 & 0 \\
\hline Beemer-1986 ${ }^{2}$ & 62 & $(62)$ & 15 & 8 & 2 \\
\hline Bevan-1988 & 113 & (76) & 12 & 5 & 3 \\
\hline Andersen-19885 & 58 & $(97)$ & 6 & 3 & 9 \\
\hline Viby-Mogensen-1979' & 68 & $(94)$ & 30 & 15 & 1 \\
\hline Brull- 1990 & 61 & $(95)$ & 15 & 1 & 0 \\
\hline
\end{tabular}

mechanographic TOF determinations as indicators of adequate clinical function. Dodgson et al. ${ }^{15}$ and Pavlin et al. ${ }^{16}$ reported that, although ventilatory function may be normal, upper airway musculature may be significantly compromised.

In conclusion, the present study emphasizes the potential for residual neuromuscular blockade in PACU patients. A better appreciation of the factors involved in residual blockade would be gained if intraoperative neuromuscular monitoring were performed quantitatively rather than qualitatively. Our data revealed that at our institution, the current intraoperative practice of clinical assessment plus neuromuscular monitoring did not necessarily prevent postoperative residual curarization, particularly in patients who received long-acting relaxants. Patients administered the shorter-acting agent vecuronium appeared to have better postoperative neuromuscular function. Train-of-four stimulation at $20 \mathrm{~mA}$ may be a sensitive method of detecting residual curarization when using a force transducer.

\section{Acknowledgements}

The authors wish to thank John Elwood CBET for his technical expertise, Jill Fuggi for preparation of the manuscript, and Theresa O'Connor MPH for providing the statistical analysis.

\section{References}

I Viby-Mogensen J, Jorgensen BC, Ording H. Residual curarization in the recovery room. Anesthesiology 1979; 50: 539-41.

2 Beemer GH, Rozental P. Postoperative neuromuscular function. Anaesth Intensive Care 1986; 14: 4l-5.

3 Lennmarken C, Lofström JB. Partial curarization in the postoperative period. Acta Anaesthesiol Scand 1984; 28: $260-2$.

4 Bevan DR, Smith CE, Donati $F$. Postoperative neuromus- cular blockade: a comparison between atracurium, vecuronium, and pancuronium. Anesthesiology 1988; 69: 272-6.

5 Andersen BN, Madsen JV, Schurizek BA, Juhl B. Residual curarization: a comparative study of atracurium and pancuronium. Acta Anaesthesiol Scand 1988; 32: 79-81.

6 Brull SJ, Silverman DG, Ehrenwerth J. Problems of recovery and residual neuromuscular blockade: pancuronium vs. vecuronium. Anesthesiology 1988; 69: A473.

7 Connelly NR, Silverman DG, $O^{\prime}$ Connor TZ, Brull SJ. Subjective responses to train-of-four and double burst stimulation in awake patients. Anesth Analg 1990; 70: 650-3.

8 Brull SJ, Ehrenwerth J, Silverman DG. Stimulation with submaximal current for train-of-four monitoring. Anesthesiology 1990; 72: 629-32.

9 Viby-Mogensen J, Jensen NH, Engbaek J, Ording $H$, Skovgaard LT, Chraemmer-Jorgensen $B$. Tactile and visual evaluation of the response to train-of-four nerve stimulation. Anesthesiology 1985; 63: 440-3.

10 Engbaek J, Ostergaard D, Viby-Mogensen J. Double burst stimulation (DBS): a new pattern of nerve stimulation to identify residual neuromuscular block. $\mathrm{Br} \mathrm{J}$ Anaesth 1989; 62: 274-8.

11 Drenck NE, Ueda N, Olsen NV er al. Manual evaluation of residual curarization using double burst stimulation: a comparison with train-of-four. Anesthesiology 1989; 70: 578-81.

12 Ueda N, Inoue S, Muteki $T$ et al. A new neuromuscular transmission monitoring system (Accelograph). The rationale behind the method and its clinical usefulness. Masui 1988; 37: 1265-72.

13 Jensen E, Viby-Mogensen J, Bang U. The Accelograph: a new neuromuscular transmission monitor. Acta Anaes. thesiol Scand 1988; 32: 49-52.

14 Brull SJ, Connelly NR, O'Connor TZ, Silverman $D G$. Consistency of accelographic train-or-four ratios at varying currents. Anesthesiology 1990, A867. 
15 Dodgson BG, Knill RL, Clement JL. Curare increases upper airway resistance while reducing ventilatory muscle strength. Can Anaesth Soc J 1981; 28: 505-6.

16 Pavlin EG, Holle RH, Schoene RB. Recovery of airway protection compared with ventilation in humans after paralysis with curare. Anesthesiology 1989; 70: 381-5.

17 Dupuis JY, Martin R, Tetrault JP. Clinical, electrical and mechanical correlations during recovery from neuromuscl:lar blockade with vecuronium. Can J Anaesth 1990; 37: $192-6$ 